\title{
Endocrine factors in palmar skin potential'
}

\author{
DON C. FOWLES AND P. H. VENABLES \\ BIRKBECK COLLEGE, UNIVERSITY OF LONDON
}

\begin{abstract}
Sodium and potassium measurements in mixed and parotid saliva were used to compute an index of mineralocorticoid activity, which was significantly related to maximum readings of palmar skin potential $(r=+0.459$ to +0.608$)$ in two experiments. These results were interpreted as indicating an important influence of the adrenal cortex in palmar skin potential, possibly reflecting stress-produced endocrine arousal.
\end{abstract}

Theories and research concerned with the mechanisms underlying palmar skin potential, a frequently used index of psychological arousal (e.g., Leiderman \& Shapiro, 1964), have been reviewed recently by Martin \& Venables (1966). These theories implicate a secretory potential in the eccrine sweat glands and/ or a passive diffusion potential due to a semi-permeable epidermal membrane. It appears highly probable, however, that in addition to any possible secretory potential there is a potential across the epithelial membrane forming the walls of the sweat gland ducts which is associated with sodium reabsorption. It is believed that an approximately isotonic fluid is secreted in the eccrine sweat glands and some salivary glands (parotid and submaxillary) and that sodium (but not potassium) is actively reabsorbed from this fluid as it passes along the duct to the surface of the skin (Guyton, 1966; Mulrow, 1967; Thaysen, 1960). This reabsorption occurs against a concentration gradient, suggesting that active transport of sodium is involved. As this process of sodium reabsorption resembles that which occurs in the distal tubules of the kidney, it is reasonable to expect that a potential difference will be established across the membrane lining the duct, as is the case in the kidney (Guyton, 1966). The exact mechanism for the production of the potential across this membrane has not been determined. It is possible that there is a sodium pump which is electrogenic (Sharp \& Leaf, 1966) or that the potential is a complicated function of the ionic concentration differences which are secondary to and dependent upon the sodium pump (Koefoed-Johnsen \& Ussing, 1960). Changes in the rate of sodium reabsorption have been related to changes in bodily mineralocorticoid activity (controlled by the adrenal cortex) in both saliva and sweat (Mulrow, 1967; Thaysen, 1960) suggesting that high membrane potentials might be associated with high mineralocorticoid activity (i.e., high sodium reabsorption). In the present experiments the analysis of sodium/potassium ratios $(\mathrm{Na} / \mathrm{K})$ in saliva provided an independent index of mineralocorticoid activity (Mulrow, 1967; Thaysen, 1960) which could then be used to determine the effects of this variable on palmar skin potential. The $\mathrm{Na} / \mathrm{K}$ scores, rather than simply $\mathrm{Na}$ values, were used because aldosterone, the most potent mineralocorticoid, causes potassium excretion as well as sodium reabsorption (Mulrow, 1967).

\section{EXPERIMENT 1}

\section{Method}

Samples of mixed saliva stimulated by chewing gum were collected from 15 Ss (ages 20-44) at the end of an experiment in which palmar skin potentials were being recorded for other purposes. An initial period of $5 \mathrm{~min}$ of chewing was allowed to remove some of the sugar from the gum and to fill the ducts with saliva secreted under reasonably standard conditions. A timed sample $(\mathrm{ml} / \mathrm{min})$ was then collected in a calibrated test tube in order to permit a correction of the sodium values for rate of salivation (Thaysen, 1960). Selective glass electrodes 2 were used to determine sodium and potassium concentrations ( $\mathrm{mEq} / \mathrm{l})$ after the saliva had been centrifuged and buffered with a mixture of diethylamine and acetic acid as recommended by Jacobson (1966) when using potassium sensitive electrodes. The buffer concentration was reduced by half in order to produce an ionic strength more suitable for the analysis of saliva. Skin potential measurements were recorded as recommended by Venables \& Sayer (1963). The active electrode was placed on the hypothenar eminence of the non-dominant hand.

As expected, it was found that the sodium concentration increases with increasing rates of salivation. The data from the 15 Ss were used to compute a regression of concentration on rate of flow $(Y=6.14 X+0.90)$, and corrected sodium values were calculated by subtracting the actual values from the values predicted by the regression of concentration on rate. The corrected sodium values were then used to compute the $\mathrm{Na} / \mathrm{K}$ scores used as an index of mineralocorticoid activity. Thus the sodium values in the $\mathrm{Na} / \mathrm{K}$ scores were not the actual sodium concentrations in saliva. Large positive values of the $\mathrm{Na} / \mathrm{K}$ score, indicating less sodium in the saliva than expected for the rate of salivation, reflected high mineralocorticoid activity, while large negative values reflected low mineralocorticoid activity. The potassium values, which were unrelated to flow, were used without correction. In order to obtain an estimate of the sweat gland potential it is necessary to avoid a loss of measured potential due to a high resistance in the sweat gland itself (e.g., as suggested by Edelberg, 1966). Consequently, the maximum skin potential reading in each S's record 
(i.e., the potential during sweat gland activity and low sweat gland resistance) was used to estimate the sweat gland potential.

\section{Results}

The correlation between the corrected $\mathrm{Na} / \mathrm{K}$ score (based on $\mathrm{Y}=6.14 \mathrm{X}+0.90$ ) and the maximum skin potential reading in the record was $0.608(p<0.02)$, indicating that Ss with high maximum skin potential readings tend to have high sodium reabsorption in saliva and, presumably, in the sweat glands.

\section{EXPERIMENT 2}

\section{Method}

Both mixed and parotid saliva were obtained. The mixed saliva (21 Ss, ages $20-47$ ) was stimulated with soft wax and collected as in Experiment 1, while parotid saliva (18 Ss, ages $20-47$ ) was stimulated by Sucaryl sweetened $1 \%$ citric acid and collected from a Lashley disc. Skin potential readings were obtained as before except that the left hand was always used. Sweat gland activity was induced by having the Ss take rapid, deep breaths and by having them say the alphabet backwards aloud.

The sodium values for both parotid and mixed saliva were corrected for the regression on rate as in Experiment 1 except that the regression for the mixed saliva was computed using data from both studies plus a third study not reported here, a total of 57 Ss. The regression equations thus obtained were $\mathrm{Y}=39.9 \mathrm{X}-$ 2.27 for parotid saliva and $\mathrm{Y}=6.94 \mathrm{X}-0.676$ for mixed saliva.

\section{Results}

The correlation between the corrected $\mathrm{Na} / \mathrm{K}$ score and the maximum skin potential was $0.459(p<0.05)$ for mixed saliva and $0.574(p<0.02)$ for parotid saliva. Using the correction for sodium based on the larger number of $\mathrm{Ss}(Y=6.94 X-0.676)$, the $\mathrm{Na} / \mathrm{K}$ scores were computed again for Experiment 1, changing the correlation with maximum skin potential slightly to 0.598 $(p<0.02)$. When the mixed saliva data from both experiments based on this correction were combined, the correlation was $0.528(p<0.002)$.

\section{Discussion}

These results support the hypothesis that sodium reabsorption in the sweat glands is an important factor in palmar skin potential. In turn, this implicates those adrenocortical hormones with appreciable mineralocorticoid activity-primarily aldosterone. At the moment it is unclear whether the variance in skin potential due to differences in sodium reabsorption reflects differences in adrenocortical activity associated with stress or whether it reflects only nonpsychological sources of error variance. It is believed that aldosterone secretion is stimulated by ACTH and that there is increased aldosterone secretion during stress (Cope, 1964), but quantitative predictions of this factor over other influences are not yet possible.

The importance of this variable in measured skin potential appears to be a function of the technique used to measure skin potential. The maximum values were observed to occur only during the initial few minutes for some Ss, indicating that hydration of the skin under the wet electrode alters the relationship between the salivary $\mathrm{Na} / \mathrm{K}$ scores and maximum skin potential. Studies are now under way to investigate more carefully the importance of the initial reading (with the skin relatively dry) vs maximum readings later in the session with fully hydrated skin.

\section{References}

COPE, C. L. Adrenal steroids and disease. London: Pitman Medical, 1964.

EDELBERG, R. Biopotentials from the skin surface: the hydration effect. Paper presented at N. Y. Acad. Sci. Conf. Bioelectrodes, June, 1966.

GUYTON, A. C. Textbook of medical physiology. (3rd ed.) Philadelphia: W. B. Saunders, 1966.

JACOBSON, H. Direct determination of sodium and potassium in the presence of ammonium with glass electrodes. Anal. Chem., 1966, 38 , 1951-1954.

KOEFOED-JOHNSEN, V., \& USSING, H. H. Ion transport. In C. L. Comar and F. Bronner (Eds.), Mineral metabolism. New York: Academic Press, 1960.

LEIDERMAN, P. H., \& SHAPIRO, D. Studies on the galvanic skin potential level: some behavioral correlates. J. psychosom. Res., 1964, 7, 277-281.

MARTIN, I., \& VENABLES, P. H. Mechanisms of palmar skin resistance and skin potential. Psychol. Bull., 1966, 65, 347-357.

MULROW, P. J. Metabolic effects of adrenal mineralocorticoid hormones. In A. B. Eisenstein (Ed.), The adrenal cortex. London: Churchill, 1967.

SHARP, G. W. G., \& LEAF, A. Studies on the mode of action of aldosterone. Rec. Prog. horm. Res., 1966, 22, 431-466.

THAYSEN, J. H. Handling of alkali metals by exocrine glands other than the kidney. In H. H. Ussing, P. Kruhøffer, J. H. Thaysen, \& N. A Thorn, The alkali metal ions in biology. Berlin: Springer-Verlag, 1960.

VENABLES, P. H., \& SAYER, E. On the measurement of the level of skin potential. Brit. J. Psychol., 1963, 54, 251-260.

Notes

1. This research was supported by Public Health Service Grants MH 25002-01 and -02 .

2. Electronic Instruments Ltd., glass electrodes BH104 and BH115. 